\title{
Micro Scale Tensile Behaviour of Thin Bitumen Films
}

\author{
L.D. Poulikakos • M.N. Partl
}

Received: 26 May 2010 / Accepted: 28 October 2010/Published online: 25 November 2010

(C) Society for Experimental Mechanics 2010

\begin{abstract}
The tensile behaviour of two types of viscoelastic bituminous films confined between mineral aggregates or steel as adherends, was investigated in the brittle and ductile regimes. Uniaxial specimens were fabricated employing a prototype set up allowing construction of micro-scale thin films and visualization of failure phenomena. The effect of key parameters, namely, temperature $\left(23^{\circ} \mathrm{C}\right.$ and $-10^{\circ} \mathrm{C}$ ), binder type (straight run and polymer modified), adherend type (stainless steel and mineral aggregate), and water conditioning were investigated sequentially. The results show that water sensitive aggregate-binder combinations in macro $(150 \mathrm{~mm}$ diameter) and mega (in service) scales also displayed reduced tensile strength in the micro scale when water conditioned. At $23^{\circ} \mathrm{C}$ ductile failure and at $-10^{\circ} \mathrm{C}$ brittle fracture were observed. At $23^{\circ} \mathrm{C}$ phenomena, such as formation of striations during tensile mechanical loading, void nucleation and growth, filamentation and large ductile flow before fracture could be witnessed. When using proper surface preparation procedures, in all types of specimen investigated at $23^{\circ} \mathrm{C}$ only cohesive failure and at $-10^{\circ} \mathrm{C}$ predominantly adhesive-cohesive failure were found.
\end{abstract}

Keywords Microscale-tensile testing · Bitumen film . Porous asphalt $\cdot$ Viscoelastic film

L.D. Poulikakos $(\bowtie) \cdot$ M.N. Partl

Laboratory for Road Engineering/Sealing Components,

Empa, Swiss Federal Laboratories for Material

Science and Technology,

Überlandstrasse 129 ,

8600, Dübendorf, Switzerland

e-mail: lily.poulikakos@empa.ch

M.N. Partl

e-mail: manfred.partl@empa.ch

\section{Introduction}

Asphalt concrete is a composite road material that consists primarily of three phases: coarse and fine mineral aggregates, air and a bituminous matrix in which the first two phases are embedded. These constituents are shown in the micrographs in Fig. 1, which show the microstructure of a typical porous asphalt specimen. The properties of asphalt concrete are a function of size, amount (distribution), shape and type of these constituents. Whereas, bitumen is a viscoelastic material and its properties are highly temperature and strain rate dependant, the aggregates behave elastically. Porous asphalt (PA) or open-graded asphalt concrete is an environmentally friendly road material due to its noise reduction properties and improved driving conditions in rainy weather. PA used in the top layers, usually has a void content of 20 vol.\% or greater. Due to higher proportions of coarse aggregates and lower sand content, interconnected micro voids are created which, in wet weather, under the action of gravity and/or capillarity, lead the water away through a series of micro conduits into a drainage system preventing aquaplaning on the road surface, spraying and splashing, and improving visibility. Furthermore, the macrotexture of the surface and the high porosity of this material result in better noise reduction performance [1].

As shown in the example of Fig. 1, bituminous binders in asphalt concrete exist in the form of thin films. Understanding the behaviour of the material as thin films is essential in understanding its fundamental properties. Microscopic observations using electron microscopes [Fig. 1(c)] show that in asphalt concrete the binder film thickness is highly irregular, it does not exist as pure binder, rather as asphalt mastic that comprises binder, filler and additives $[2,3]$. However, extensive conclusive research on 
Fig. 1 Microstructure of porous asphalt: (a) Thin section (Dimensions: $28 \times 47 \mathrm{~mm}^{2}$ and a thickness of $25-30 \mu \mathrm{m}$ ) showing voids filled with epoxy resin in yellow (1), mastic (bitumen + filler + additives) in black (2) and aggregates in grey (3). (b) Optical micrograph showing detail of thin film of mastic in black and mineral aggregates. (c) Electron micrograph showing detail of mastic; filler particles in grey, bitumen in black and SBS polymer modification in white

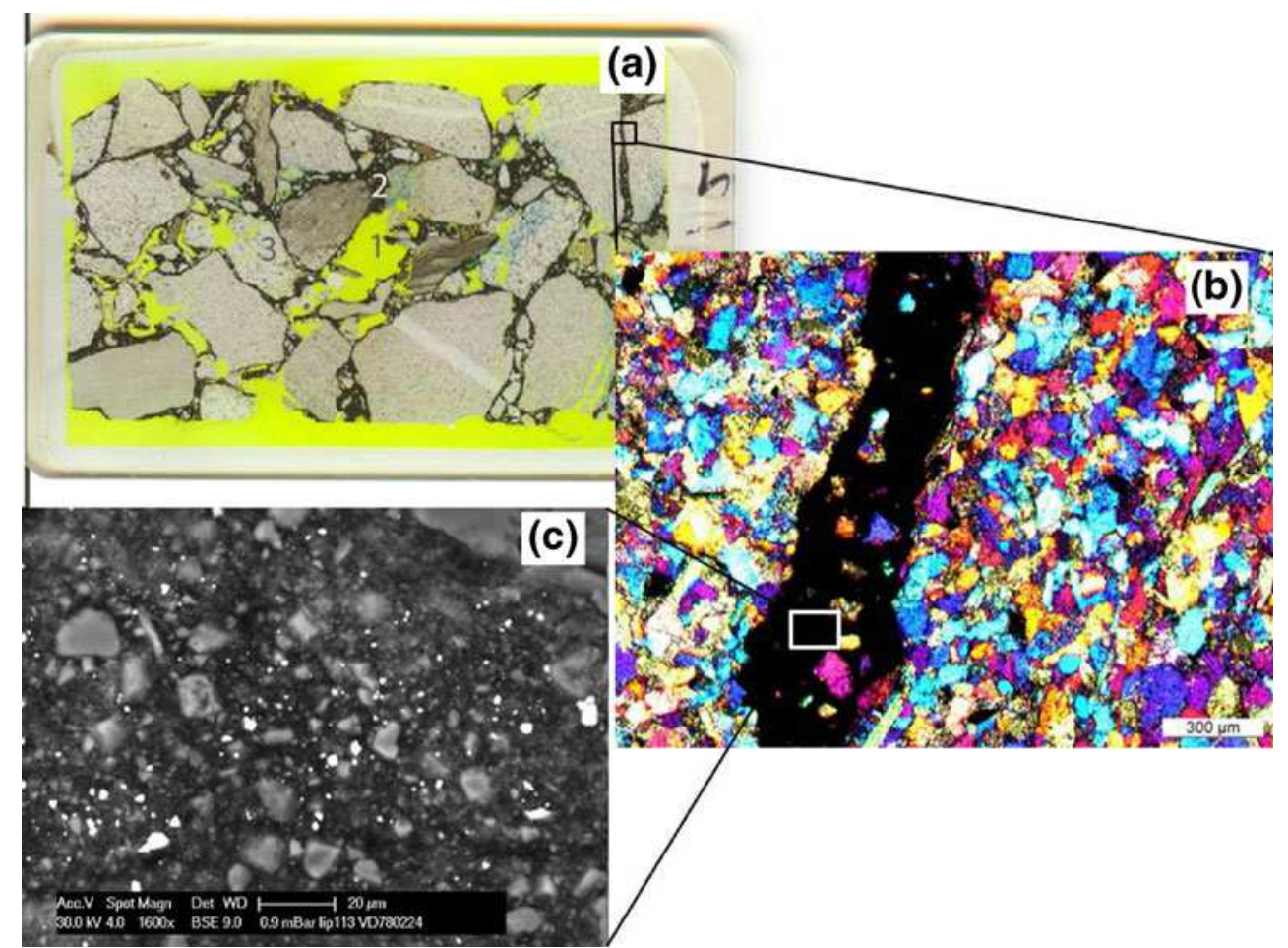

thin binder films has not been performed so far. Recently, Harvey and Cebon $[4,5]$ have investigated bitumen films of 0.5 to $3 \mathrm{~mm}$ thickness at temperature range of -30 to $30^{\circ} \mathrm{C}$ and tension strain rates of 0.03 to $100 \mathrm{~s}^{-1}$. Fracture properties of $320 \mu \mathrm{m}$ thin films of straight run bitumen were investigated by Hammoun et al. [6] who studied the evolution of crack size with numerical methods.

Already in 1967, Marek and Herrin [7] explored the tensile behaviour of thin films of bituminous binders. The main parameters studied were film thickness (20 to $600 \mu \mathrm{m})$, rate of deformation $(0.125$ to $25 \mathrm{~mm} / \mathrm{min})$, temperature $\left(0\right.$ to $\left.50^{\circ} \mathrm{C}\right)$, penetration $(50$ to 217$)$ and source of bitumen. In their investigation, three main regions to the tensile strength-log film thickness relationship were identified. The tensile strength reaches a peak, referred to as optimum binder film thickness. For the binders tested this peak was at about $20 \mu \mathrm{m}$. The region below this peak is referred to as region I. The results obtained from the first region with extremely thin films had limitations due to preparation techniques, since fabrication of uniform thin films was difficult. They have shown that in region II (20 to $100 \mu \mathrm{m})$ a straight line relationship exists between tensile strength and film thickness indicating an inversely proportional relationship of the two. In region III, for thick films (thickness $>100 \mu \mathrm{m}$ ), a nearly horizontal line was found. This relationship between binder thickness and tensile strength was observed irrespective of other studied parameters mentioned earlier.

Switzerland started using PA in 1979 with mixed results and according to a survey taken in 2004, only nine of the
26 Cantons use PA. A national cooperative research project funded by the Swiss federal government was initiated to explore the mechanical performance of PA in Switzerland [8]. In this study, various mechanical tests were performed on laboratory prepared specimen and cores taken from pavements, selected based on feedback from various Cantons in the survey. Laboratory tests allowed the comparison of core performance with that of laboratory prepared specimen, as well as comparison with field performance. The laboratory samples $(150 \mathrm{~mm}$ diameter cylindrical specimen) provided information about the mechanical behaviour of the materials in the macro scale and the field performance provided information in the mega scale $[8,9]$. This paper investigates the material in the thin film region referred to region I [7]. The information obtained provides a foundation to compare the mechanical behaviour of the material from micro to mega scales.

\section{Causes of Degradation of Porous Asphalt}

Although PA is a modern road material with many advantages, due to its high porosity, when compared to dense asphalt concrete, it deteriorates faster and must be replaced at substantial economic costs. Therefore, understanding the process of deterioration and exploring avenues of material improvement is of great importance.

Degradation of PA can occur under static and dynamic mechanical loading and environmental exposure. Due to its porous nature, PA is more susceptible to oxidation due to 
contact with air, photochemical deterioration at its surface and contact with water throughout its structure. The mineral aggregates if properly covered with the binder can be considered to be practically immune to environmental effects. However, microstructural observations [2] have shown that uncovered aggregates are not uncommon in the mix. In addition, the deterioration of the mineral aggregates is primarily due to mechanical loading. Investigation of the microstructure of PA has also shown the existence of relatively few micro-cracks in the mineral aggregates during the in situ compaction process and after exposure to traffic loads. This is due to the fact that according to the standards [10], high quality aggregates are required for PA. Therefore the deterioration of PA is primarily due to the deterioration of the bituminous binder film resulting in the loss of cohesion and loss of adhesion.

Moisture infiltration leads to loss of strength and durability and ultimately results in ravelling and stripping attrition. Progressive moisture damage in combination with mechanical load due to traffic can lead to failure of the road over time. Due to its chemical and physical nature, as moisture reaches the binder-aggregate interface, preferential bonding of water molecules with the aggregate molecules can result in de-bonding of the binder from aggregate surface [11]. In the ideal case where there is continuous coverage of the aggregates by the binder, it was suggested by Kringos (2007) [12] through experiments and modelling, that water can reach the aggregate surface by diffusion process. Cheng [11] has experimentally investigated the diffusion of moisture vapour into various bituminous binders and has also shown that this diffusion is binder dependent.

\section{Scope}

The development and use of porous asphalt has posed new questions to be answered in terms of mechanical performance and deterioration of bitumen films. First, the influence of water becomes imperative in characterizing material behaviour. Second, PA requires the use of new binder modifiers such as polymers [10] and their influences need to be investigated. Due to experimental limitations at the time of Marek and Herrin [7], there exists a gap in knowledge for the first thin film region I $(\mathrm{t} \leq 20 \mu \mathrm{m})$. In addition, the influence of mineral aggregate adherends was not considered. More recently, it was shown that $20 \mu \mathrm{m}$ is a binder thickness that indeed exists in asphalt concrete $[2,3]$. It was also shown that there exists a strong dependency of tensile strength of binder films on their thickness and that the highest strength regardless of temperature or strain rate, is at around $20 \mu \mathrm{m}$ film thickness [7].
The research reported herein aims at contributing in closing the gap in knowledge in this area. To this end, a conceived novel approach for the fabrication of binder films is presented. The fabrication of specimen with $20 \mu \mathrm{m}$ thin films was realized employing a prototype set up designed and fabricated for this purpose. As shown in Table 1, the tensile behaviour of two types of bituminous binder films confined between both aggregates and steel adherends was tested. The effect of two temperature extremes of practical importance to rather cold climates such as that found in Switzerland $\left(23^{\circ} \mathrm{C}\right.$ and $\left.-10^{\circ} \mathrm{C}\right)$, the binder type (straight run and polymer modified) and the effect of water conditioning were investigated. Although a pure bitumen film does not exist in a real pavement environment, rather a combination of bitumen, filler and additives known as mastic (Fig. 1), for the purpose of simplification and since fundamental aspects of the binder behaviour are sought in this study, as a first step pure bitumen was used in order to gain basic knowledge of the behaviour of this material. An important goal of this investigation was to determine if the difference in performance of these materials seen in macro and mega scales [8, 9], can also be observed and quantified in microscale mechanical tests indicating that it is the microscale where performance determining phenomena find their origin.

\section{Materials}

The PA materials in this study were chosen based on two different mixes used in Switzerland in Cantons Aargau (AG1) and Vaud (VD4) with known in situ performance. Composition of these two materials differ firstly in the aggregate type and gradation and secondly in the type and content of the bituminous binder (Table 2) [2, 8]. Composite material A, which is based on AG1 contains straight run bitumen B55/70 and composite material B, which is based on VD4, contains polymer modified

Table 1 Types of investigated micro-tensile specimens

\begin{tabular}{lll}
\hline Designation & Binder & Adherend \\
\hline A & B55/70 & Steel \\
$\mathrm{Aw}$ & B55/70, water cond. & Steel \\
$\mathrm{B}$ & PmB 65A & Steel \\
$\mathrm{Bw}$ & PmB 65A, water cond. & Steel \\
$\mathrm{Ab}$ & B55/70 & Balmholz mineral \\
$\mathrm{Abw}$ & B55/70, water cond. & Balmholz mineral $^{\mathrm{a}}$ \\
$\mathrm{Bc}$ & PmB 65A & ${\text { Choëx mineral }(2)^{\mathrm{b}}}^{\mathrm{a}}$ \\
$\mathrm{Bcw}$ & PmB 65A, water cond. & ${\text { Choëx mineral }(2)^{\mathrm{b}}}$ \\
\hline
\end{tabular}

${ }^{\mathrm{a}}$ Siliceous limestone, ${ }^{\mathrm{b}}$ Sandstone 
Table 2 Standard characteristics of the materials

\begin{tabular}{llll}
\hline Binder Properties & Penetration Graded Binder type & B 55/70 & PmB ${ }^{\mathrm{a}}$ 65A \\
& Penetration at $25^{\circ} \mathrm{C}[0.1 \mathrm{~mm}]$ & 18 & 50 \\
& Softening point $\left[{ }^{\circ} \mathrm{C}\right]$ & 72.2 & 56.6 \\
& $\mathrm{Tg}\left[{ }^{\circ} \mathrm{C}\right]$ & -29 and 2.4 & -20.48 and 14.7 \\
Mineral Aggregate Properties & Aggregate type & Siliceous limestone & Quartz sandstone \\
& Los Angeles abrasion test (LA) $[\%]$ & $13-18$ & $<18$ \\
& Polished Stone Value test (PSV) & 53 & $>50$ \\
\hline
\end{tabular}

${ }^{\text {a }}$ Polymer modified bitumen Styrelf $13 / 80$ with SBS polymer modification

bitumen with styrene butadiene styrene co-polymer (SBS). Polymer modification of the binder is required by the current Swiss standards for porous asphalt [10]. SBS is an elastomer that is mostly used for improving the rheological properties of bitumen and, as a result, the performance of PA [13].

The aggregates were supplied by local quarries. Mineral aggregates for material A are silicius limestone which comes from the Balmholz quarry located at Lake Thun in central Switzerland. The mineral from this quarry falls in the sedimentary rock category. Siliceous Limestone from Balmholz is a hard dark grey stone with sharp edges when crushed. It is known to have high pressure and abrasion resistance as well as good water resistance (Table 2). Mineralogical data indicate $30 \%$ to $45 \%$ of quartz by mass. The primary source of the calcite in limestone is marine organisms [14].

The mineral aggregate used in material $\mathrm{B}$ is from the Famsa quarry in Massongex in Canton Valais in eastern Switzerland. It is a hard sand stone from the sedimentary rock category with $20-30 \%$ quartz (Table 2) [15]. As shown in Table 2 the aggregate characteristics determined through standard industry tests such as the resistance to fragmentation test (LA) [16] and polished stone value test (PSV) [17] are similar. Additionally, the mineral gradation, binder content and void content of the two materials are almost identical $[2,8]$.

In situ performance of the two materials differs in terms of early signs of poor adhesion of material $\mathrm{A}$ as compared to material B. The PA from Canton Aargau upon which material A is based, had to be replaced prematurely at considerable costs due to its excessive ravelling. On the other hand, the pavement material B is based on was seven years in service with satisfactory results when the investigated cores were extracted and performed well in laboratory tests $[2,8]$.

\section{Sample Fabrication}

In order to determine the tensile behaviour of bitumen films, two types of uniaxial tensile specimens, shown in Fig. 2, were prepared. The dog-bone shape of the samples with a gap to be filled with binder allows for clamping in the test apparatus. A uniform tensile stress field can be transferred to the binder, independent of clamping effects and the effected localization of the failure location allows for better observation. The stainless steel insets contain a pin hole for pulling the sample in tension. The first type of specimen with binder confined between two steel adherends was used to investigate the binder behaviour independent of the influence of the aggregates. The second type of specimen included the binder confined between two mineral aggregate adherends and allowed to study the influence of binder aggregate bond on mechanical behaviour. The stainless steel and mineral aggregate adherends attached to the thin bitumen film have much
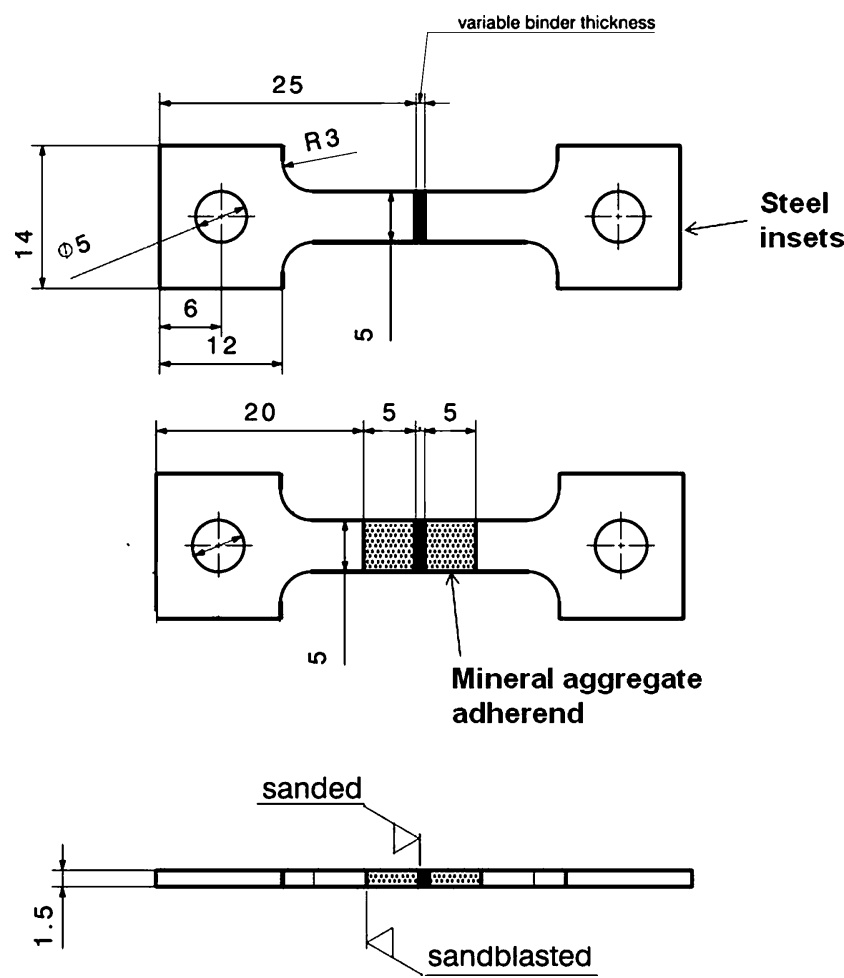

Fig. 2 Diagram of the tensile test specimens. Top: Specimen for binder film tests with stainless steel adherend. Below: specimen for binder film tests with mineral aggregate adherend. Dimensions in $\mathrm{mm}$ 
greater stiffness in comparison to the bitumen film and their deformation is negligible in the experiments.

\section{Contact Surface Preparation}

Surface preparation is essential for a proper bond. All relevant surfaces of the adherend (stainless steel and mineral aggregates) where cleaned and abraded in preparation for bonding. All surfaces were lightly abraded in order to insure better bonding. The abrasion of the metal surface was performed by sand blasting whereas the abrasion of the mineral aggregate by sanding with a 1000 grit $\mathrm{SiC}$ sandpaper three times in each perpendicular direction. Grease and loose surface deposits were removed with an acetone soaked cloth and high pressure air, respectively. Surfaces where bonded immediately after pre-treatment when the surface conditions were optimum (clean and free of debris as described above).

The aggregates were epoxied to the stainless steel surface using $\operatorname{Araldit}^{\circledR}$ multi purpose two component adhesive at room temperature. Araldit ${ }^{\circledR}$ forms extremely strong and durable bonds and solidifies within minutes. After drying overnight, the excess adhesive was sanded off to create a smooth transition surface between aggregates and steel.

\section{Specimen Assembly in Mold}

In order to construct a specimen with $20 \mu \mathrm{m}$ thin film, a prototype assembly mold was designed and a thirteen step assembly protocol that includes surface preparation was developed and summarized below. The schematic diagram in Fig. 3 shows the setup for tensile specimen fabrication with three intermediate steps. Temperature plays a key role in the assembly process. Hence, bitumen was heated in a forced convection oven for a minimum of $30 \mathrm{~min}$ and maximum of $2 \mathrm{~h}$ at the binder mix temperature $\left(\mathrm{ca} .150^{\circ} \mathrm{C}\right.$ ). The aim was to heat the binder in the preparation process as little as possible just reaching the liquid state, altering its physical properties as marginally as possible while, at the same time facilitating adhesion. The tensile insets were heated locally shortly on the Bunsen burner in order to bring about the adhesion of the binder. Thereafter, the tip of the insets were dipped in the hot bitumen and placed immediately in the frame. The distance was adjusted using the micrometer to the required binder film thickness. The specimen was stabilized with a brace system [Fig. 3(b)]. Subsequently, the specimen and the brace were removed from the frame, the excess binder was removed immediately using a heated spatula and the assembly was left to set overnight [Fig. 3(c)]. The entire assembly process takes less than 5 min. Observing a precise sample fabrication protocol proved to be essential for sample quality and repeatability (a)

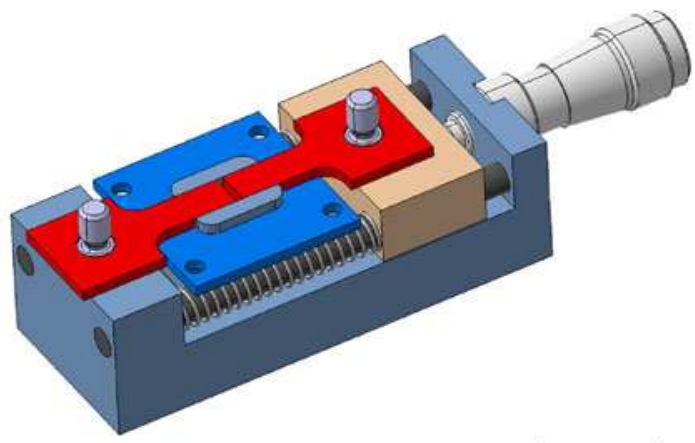

(b)

micrometer

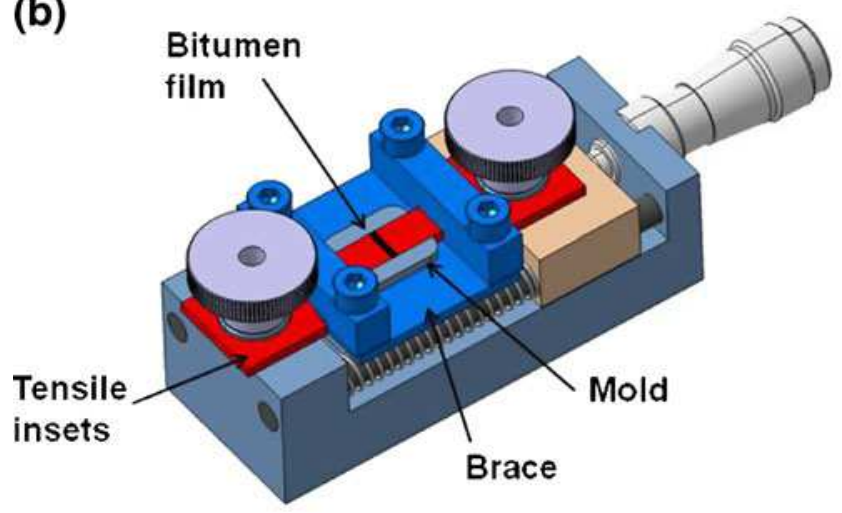

(c)

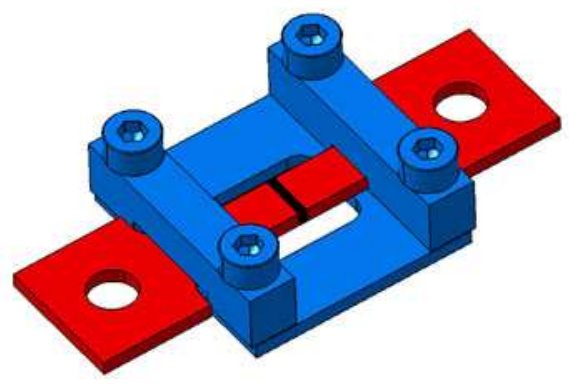

Fig. 3 Schematic diagram showing the setup for tensile specimen fabrication: (a) Specimen placed on frame over brace. (b) Binder placed between tensile end insets, binder thickness adjusted. (c) Specimen with brace ready to be placed in the tensile machine

as confirmed by the premature failure of samples before this protocol was developed.

The specimens are approximately $50 \mathrm{~mm}$ long including the end insets, which are made of stainless steel. The binder has a nominal cross sectional area of $5 \mathrm{~mm}$ by $1.5 \mathrm{~mm}$. As explained earlier, based on microstructural observations and previous work [7] a binder thickness of $20 \mu \mathrm{m}$ was chosen. This film thickness size results in an aspect ratio of 250 , that defines it as a thin film (>8) according to Harvey and Cebon $[4,5]$ and according to Marrek and Herrin (region I) [7]. The mineral aggregates were sawed from an $11 \mathrm{~mm}$ aggregate to $5 \mathrm{~mm}$ by $5 \mathrm{~mm}$ and $1.5 \mathrm{~mm}$ thick.

The key parameters of interest were: bituminous binder type (straight run or polymer modified), temperature (23 and $-10^{\circ} \mathrm{C}$ ), water conditioned or not and type of adherend (stainless steel or mineral aggregate). In order to study these 
parameters four types of samples for each binder type were produced as shown in Table 1. The binder-aggregate combinations reflect the mix as placed in situ.

\section{Microtensile Experimental Setup}

In order to investigate the tensile properties of the selected specimens (Table 1), simple fracture tests using uniaxial tensile loads were designed where the separation of the specimen was induced through a static displacement using the Zwick ${ }^{\circledR}$ apparatus. The Zwick ${ }^{\circledR}$ apparatus consists of a testing machine to apply tensile load using a $20 \mathrm{~N}$ load cell for tests at $23^{\circ} \mathrm{C}$ and a $100 \mathrm{~N}$ load cell for tests at $-10^{\circ} \mathrm{C}$ and an extensometer and grips to hold the specimen. A grip system to hold the specimen was especially designed for this experiment. An upper and lower alignment rod is used to align the loading frame and load cell. Strain is measured by an extensometer (Multisense ${ }^{\circledR}$ ) that is fixed to the specimen using two knife edges a distance $\mathrm{L}_{0}$ apart (Fig. 4).

The specimen was placed in the tensile machine and kept aligned and in place using two rods. Thereafter, the brace that had kept it stable was carefully removed (Figs. 3 and 4). Using constant deformation rate the specimen was extended.

\section{Test Parameters}

It has been established that the behaviour of bitumen films is highly temperature and strain rate dependent $[4,5,7]$. Specifically, as the strain rate is increased, the tensile

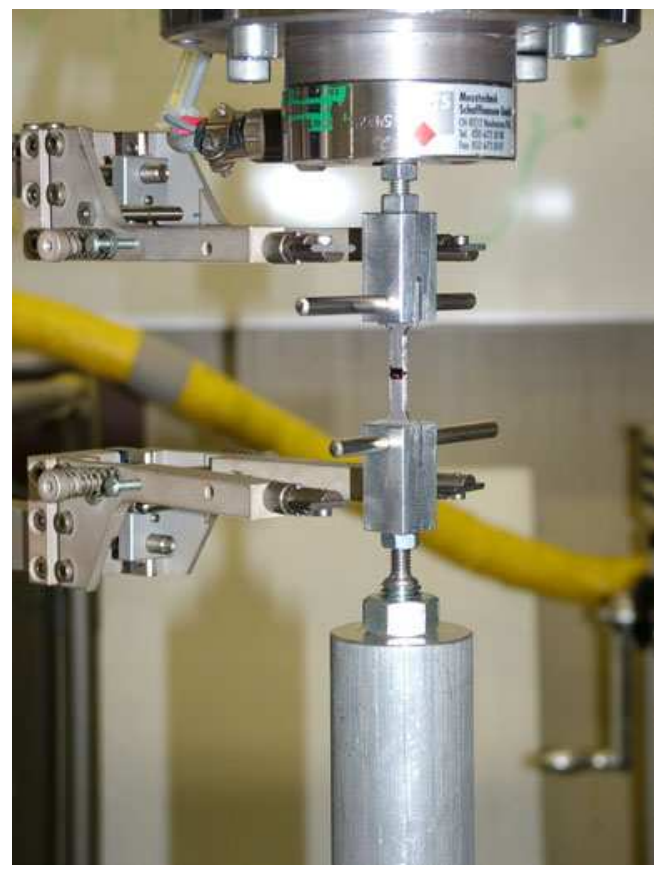

Fig. 4 Experimental set up for the binder tensile strength test at $23^{\circ} \mathrm{C}$ strength of a bituminous film at a given temperature and thickness will increase [7]. Furthermore, depending on the strain rate, the material can exhibit ductile or brittle failure. For the current tests through trial and error an optimum deformation rate of $0.1 \mathrm{~mm} / \mathrm{min}$ was obtained in order to assure ductile behaviour at $23^{\circ} \mathrm{C}$. This deformation rate lies in the lower part of the spectrum examined previously, namely, at $0.125 \mathrm{~mm} / \mathrm{min}$ [7] and allows some basis for comparison of results.

Depending on the temperature, the same binder can exhibit brittle, brittle-ductile or ductile behaviour in tension. The tests presented herein in the ductile regime were performed at $23^{\circ} \mathrm{C}$ and in the brittle regime at approximately $-10{ }^{\circ} \mathrm{C}$ and $50 \%$ and $2 \%$ relative humidity, respectively. For low temperature tests a climate chamber was used, whereas the tests at $23^{\circ} \mathrm{C}$ were performed in a conditioned room. The low temperature tests were chosen to be below the glass transition temperature (Tg) and clearly in the brittle regime (Table 2) as seen from the resulting mechanical behaviour. Tg was measured using the differential scanning calorimetry (DSC) method [18]. Above Tg, thermal activation is large enough to overcome the intermolecular bonds and the mobility of the molecules increase resulting in a completely different mechanical performance.

Water conditioning on all types of specimen allowed observing the effect of water on bitumen film type (polymer modified or straight run) and bitumen film and adherend combinations during direct tension testing. For this purpose, the samples were conditioned in water for $17 \mathrm{~h}$ at room temperature (ca. $22^{\circ} \mathrm{C}$ ). This choice of water conditioning time allowed the samples to be tested rapidly after fabrication and as demonstrated later change in mechanical properties was observed. If no change was observed this time would have been extended.

\section{Results and Discussion}

The tensile tests allow the characterization of the linear and non-linear elastic-plastic behaviour of the material using stress-strain diagrams. Due to constant deformation rate in these series of experiments time effects and therefore viscoelastic behaviour of the material could not be taken into account. Due to this, in the following, the linear and nonlinear part of the stress-strain diagram will be referred to as "elastic" and "plastic" respectively. However, from the stress-strain diagram important mechanical properties such as the elastic modulus, the maximum tensile stress, the nominal strains, the energy required for the material to mechanically fail and the ductile characteristics have been determined. Depending on the temperature, during the tensile tests, the materials deformed elastically and plasti- 
cally and the resulting brittle or ductile failure was documented.

In order to understand the mechanical behaviour of the material, it is helpful to study its molecular structure. Bitumen is a polymeric material that consists of a complex chemical mixture of various molecules that are predominantly hydrocarbons with a small amount of sulphur, nitrogen and oxygen atoms [19].The mechanical properties of such materials are determined by the mobility of the molecules, which in turn depend on their chemical structure i.e. geometry of the molecular structure and inter-atomic and intermolecular bond. Both elastic and plastic behaviour of polymers is time dependent and therefore viscoelastic and viscoplastic. At small strains the material behaviour is linear viscoelastic. Elastic deformations are due to reversible deformation of the molecules and are due to weak intermolecular van der Waals, dipole or hydrogen bonds that are strained. The inter-atomic covalent bonds do not contribute significantly to the elastic properties because they are much stronger than the secondary bonds. When unloaded the molecules return to the equilibrium positions. During plastic deformation, disentanglement of polymer molecular chains or sliding of chains past each other produce permanent deformation [20,21].

The characteristic nominal stress-strain diagram for $20 \mu \mathrm{m}$ bitumen film at $23^{\circ} \mathrm{C}$ is shown in Figs. 5 and 9 and at $-10^{\circ} \mathrm{C}$ in Fig. 10 . In the tests, commonly, the initial part of the curve is not straight due to initial adjustment of the specimen in the loading frame and does not represent a property of the material. Figure 9 shows a representative sample of four types of specimen for each material resulting is eight types of samples (A, Aw, Ab, Abw, B, $\mathrm{Bw}, \mathrm{Bc}, \mathrm{Bcw}$ ) as listed in Table 1. The representative samples exhibited maximum nominal tensile stress values that were closest to the mean for that type of material, with the exception of Abw, which was higher than the mean shown in Table 3.

All samples tested at $23^{\circ} \mathrm{C}$ exhibited four apparent stages leading to ultimate separation as discussed below (Figs. 5 and 6). At $23^{\circ} \mathrm{C}$ (Fig. 5) after the initial effects, the specimen behaviour is linear with a clear "Hookean region" (Stage 1). At this stage, the material did not display any observable changes in its appearance. With increasing deformation, material starts to yield and visco-plastic deformation is initiated. It was not possible to determine the exact location where the material yields, because yielding was gradual and the transition between elastic and plastic behaviour was not specified precisely.

Upon further elongation, the nominal stress increases and reaches a maximum value, vertical striations appear and the specimen starts to neck (Stage 2). This is referred to as the hardening part of the curve. From the molecular point of view the polymer chains untangle and orient themselves in the direction of stress i.e. the axial direction. The axial elongation causes lateral contraction and necking. The shape of the lateral surface is circular due to surface tension of bitumen as seen in Fig. 7(a). Necking results in a decrease of the cross sectional area and increase in true local stress. Because the cross sectional area is decreased at this point less force is needed to deform the material. The
Fig. 5 Typical stress-strain diagram for the uniaxial tension tests at $23^{\circ} \mathrm{C}$

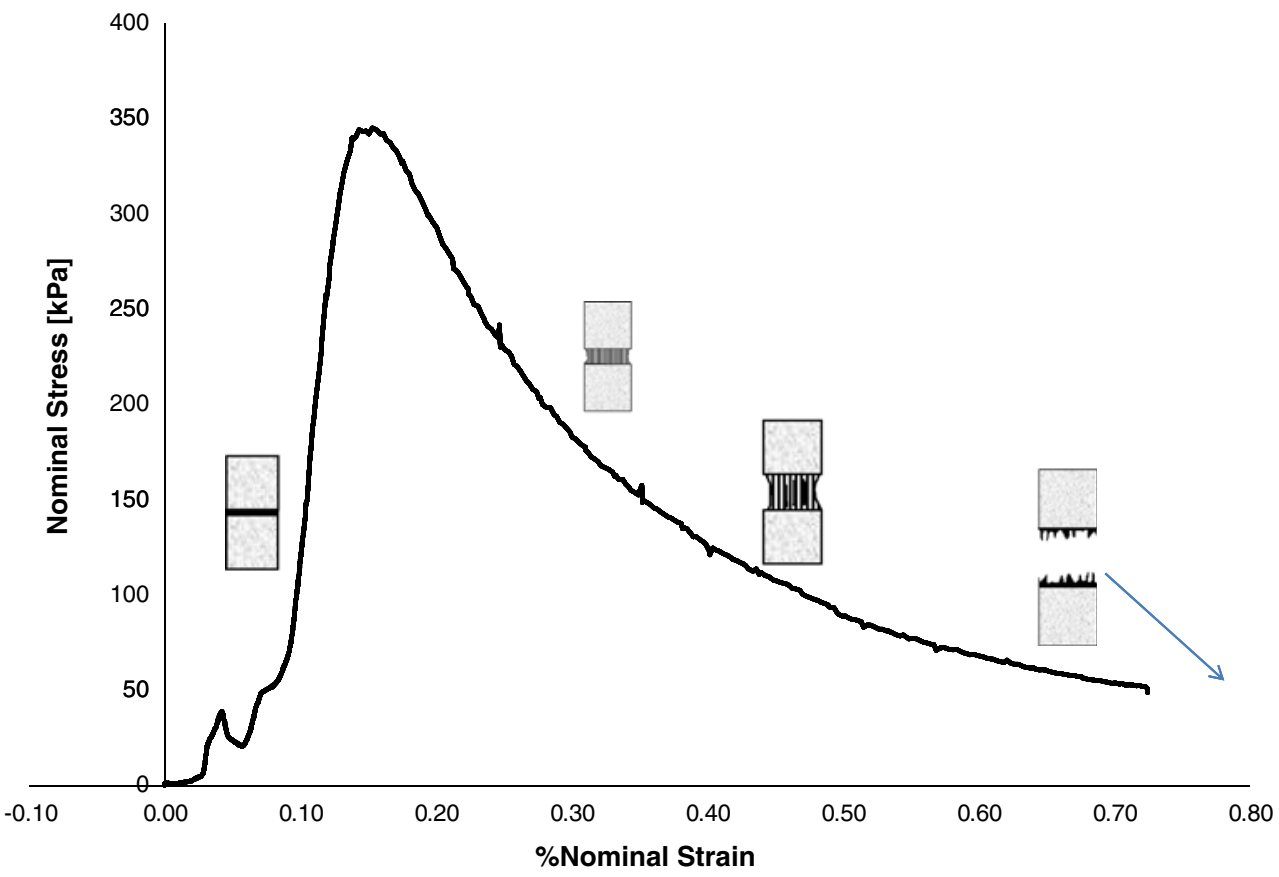


Table 3 Mechanical properties at $23^{\circ} \mathrm{C}$ and $-10^{\circ} \mathrm{C}$

\begin{tabular}{|c|c|c|c|c|c|c|c|c|c|}
\hline \multirow[t]{2}{*}{ Spec type } & \multicolumn{3}{|c|}{ Mean mechanical properties at $23^{\circ} \mathrm{C}$} & \multirow[t]{2}{*}{ W failure $[\mu \mathrm{J}]$} & \multirow[t]{2}{*}{$\mathrm{E}[\mathrm{kPa}]$} & \multirow[t]{2}{*}{$\mathrm{D}[\mathrm{kPa}]$} & \multicolumn{3}{|c|}{ Mean mechanical properties at $-10^{\circ} \mathrm{C}$} \\
\hline & Fmax $[\mathrm{N}]$ & $\sigma \max [\mathrm{kPa}]$ & $\varepsilon @ \sigma \max [\%]$ & & & & Fmax $[\mathrm{N}]$ & $\sigma \max [\mathrm{kPa}]$ & $\varepsilon @ \sigma \max [\%]$ \\
\hline $\mathrm{A}$ & 3.39 & 456.90 & 4.79E-02 & 86.84 & 1638.60 & -287.04 & 33.08 & 4455.53 & 0.010 \\
\hline Aw & 2.86 & 385.16 & 4.87E-02 & 123.94 & 1228.80 & -488.87 & & & \\
\hline $\mathrm{Ab}$ & 3.40 & 457.40 & $6.98 \mathrm{E}-02$ & 151.07 & 1014.10 & -255.07 & 27.45 & 3696.70 & 0.047 \\
\hline Abw & 1.88 & 252.76 & $6.50 \mathrm{E}-02$ & 47.60 & 900.03 & -262.17 & & & \\
\hline $\mathrm{B}$ & 1.21 & 163.53 & $3.35 \mathrm{E}-02$ & 41.08 & 792.90 & -67.23 & 8.06 & 1085.45 & 0.050 \\
\hline $\mathrm{Bw}$ & 1.33 & 179.47 & 5.39E-02 & 69.74 & 411.08 & -80.42 & & & \\
\hline $\mathrm{Bc}$ & 1.42 & 191.60 & 4.04E-02 & 43.53 & 680.95 & -72.26 & 11.63 & 1565.70 & 0.006 \\
\hline $\mathrm{Bcw}$ & 0.99 & 133.48 & 7.63E-03 & 24.55 & 433.47 & -67.64 & & & \\
\hline
\end{tabular}

nominal stress decreases as it is calculated using the original area.

Further elongation resulted in further plastic deformation, softening and appearance of voids and filamentation referred to Stage 3 [Fig. 7(b and c)]. Within the filaments the molecular chains become oriented. The process of filamentation before separation absorbs fracture energy, increases fracture toughness (ability to absorb energy up to fracture) resulting in improved material performance. This phenomenon was seen in field samples as shown in the electron micrograph of Fig. 8 that shows the filamentation process and formation of fibrils within a crack. Additionally, the contact angle between binder and adherend remains well under $90^{\circ}$ throughout, indicating good wetting and adhesion (Fig. 7). Under axial load an elastic material would wrinkle as shown by Cerda and Mahadevan [22]. However, a viscoelastic material can flow viscously from the stationary plate (bottom) towards the moving top plate as shown by Yao and Mckinley [23] for axisymetric geometries. Additionally, due to surface tension apparent from the curved free surface, there is an increased mass loss in the centre. The flow should resemble flow in a channel with slip on the walls (in this case the free surface) resulting in maximum axial velocity at the centreline causing material depletion and void formation at this location as shown in Fig. 7(b). The observed formation of voids after yield for the uniaxial loading tested herein does not exactly corroborate the findings of Harvey and Cebon [4] where voids occurring well before yield are reported. However, it should be noted that the voiding process in their work could indeed be visualized for corn syrup eventhough not for bitumen; this was primarily due to the chosen geometry. After reaching the maximum, the nominal stress decreases until it reaches a steady state. Large visco-plastic deformations before rupture have occurred during these tests, which is indicative of the ductile behaviour of bituminous binders.

Stage 4 was the further elongation and merging of the voids and final separation. At $23^{\circ} \mathrm{C}$ the separated material was frayed, coming to a point at several locations (Fig. 6). Furthermore, at $23^{\circ} \mathrm{C}$ the only type of failure observed was cohesive failure for all eight types of specimen tested. Cohesive failure was confirmed by examination of the
Fig. 6 Four stages were observed in the uniaxial tension tests at $23^{\circ} \mathrm{C}$

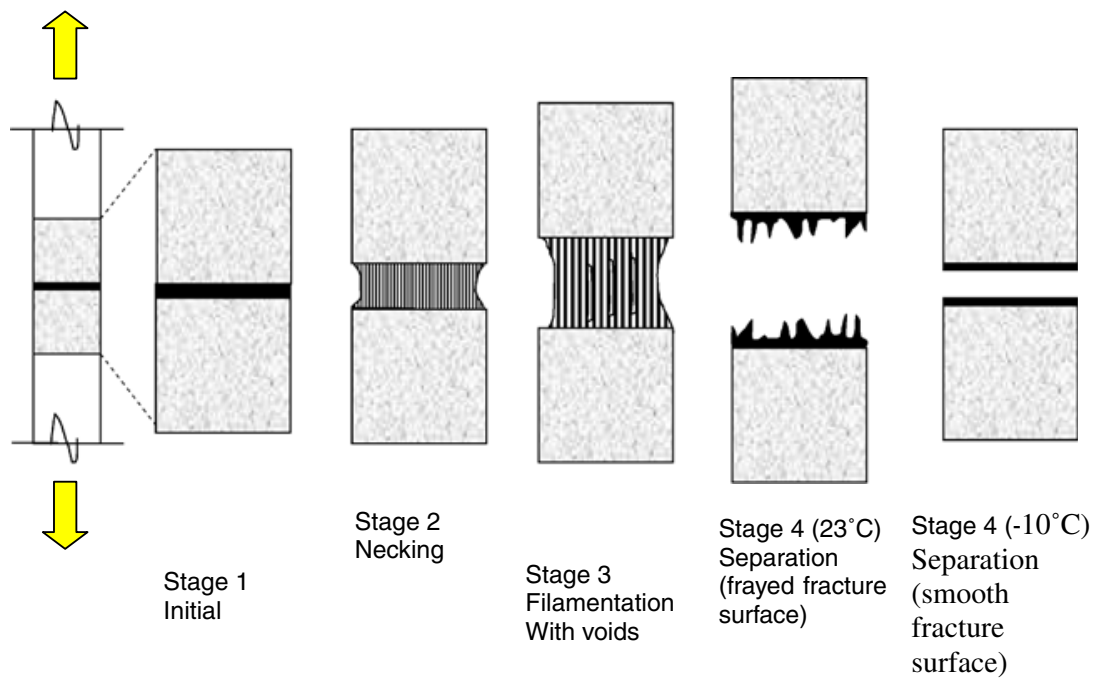


Fig. 7 (a) Photograph shows specimen $\mathrm{Bc}$ at stage 2-necking and the formation of vertical striation during the tension test at $23^{\circ} \mathrm{C}$. (b) Specimen $\mathrm{Bc}$ at stage 3-formation of voids and filamentation. (c) Specimen Bw shortly before stage 4-separation
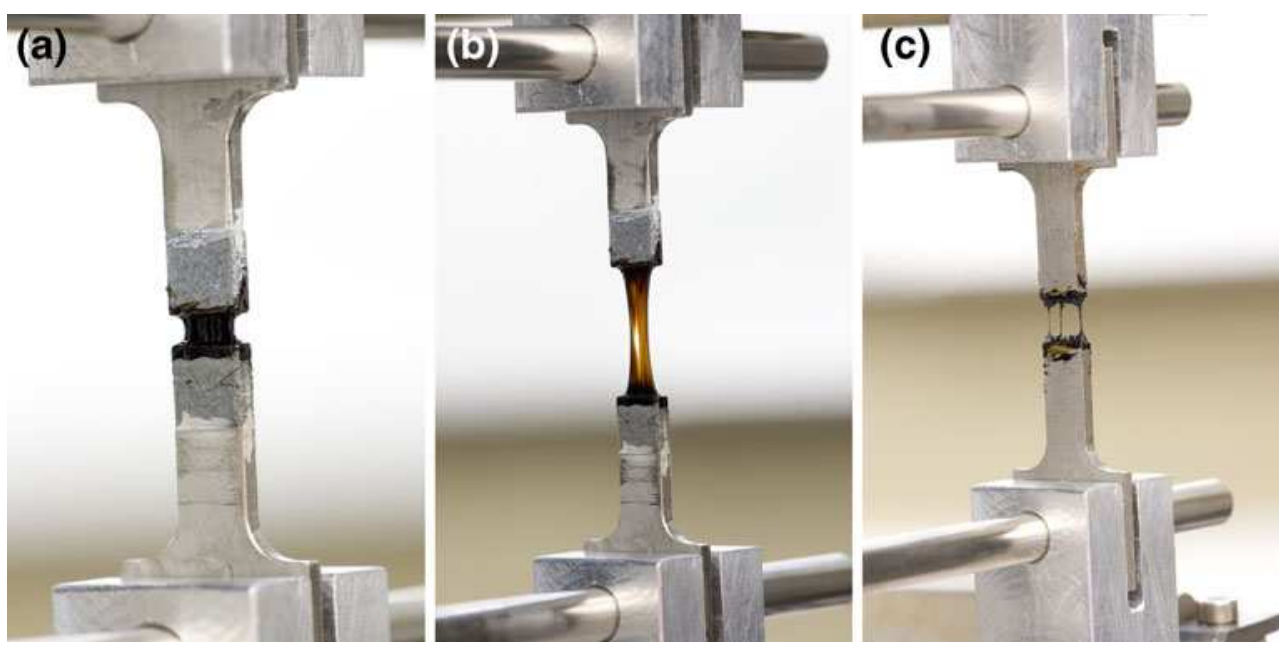

fracture surfaces with the binder leaving a continuous film on both fracture surfaces. This characteristic failure indicates good adhesion between the binder and the steel or between the binder and the mineral aggregate surfaces. Previous findings indicated also solely cohesive failure in binder films in the temperature and thickness range of interest [7].

Specimen tested at $-10^{\circ} \mathrm{C}$ displayed elastic behaviour. The only failure mode was brittle for all four types of specimen tested ( $\mathrm{A}, \mathrm{B}, \mathrm{Ab}, \mathrm{Bc})$. Binder $\mathrm{B}$ showed minimal fibril formation that could keep the sample together even after crack formation. This can be attributed to the long cross-linked molecular chains of SBS that delay separation. In most samples, a consecutive crack growth was observed with failure occurring in steps as seen in the sample stress strain diagram in Fig. 10. The non-smooth curve in Fig. 10 is indicative of small strains at the measurement limit where the influence of noise is apparent. Examination of the failure surface indicated a cohesive or adhesive-cohesive failure. No voiding was observed at the low temperature regime in both materials.

Material parameters of nominal stress $\sigma(1)$ and nominal strain $\varepsilon$ (2) are calculated form the measurements of force

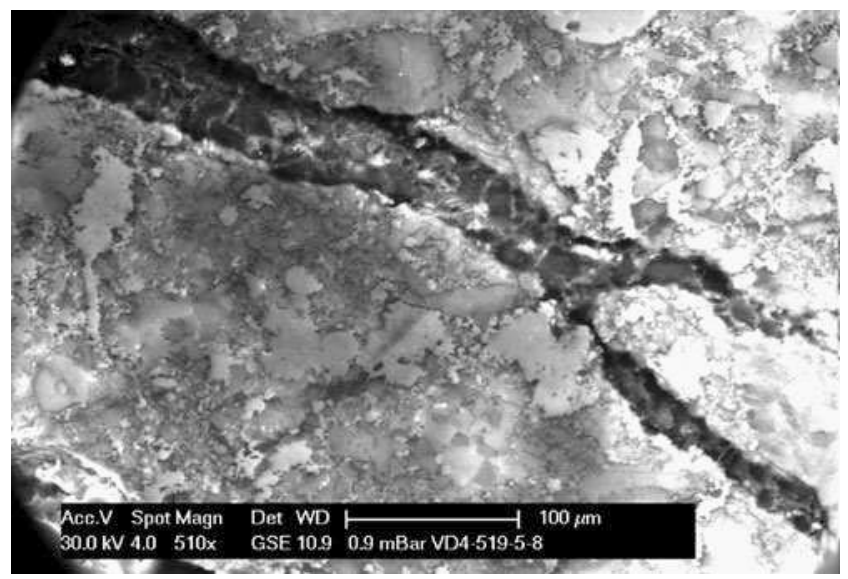

Fig. 8 ESEM GSE image showing formation of fibrils within the crack
(F) and displacement (s) as defined below and their mean values are listed in Table 3:

$\sigma=\frac{F}{A_{0}}$

$\varepsilon=\frac{\Delta s}{L_{0}}$

In the above equations, $\mathrm{A}_{0}$ and $\mathrm{L}_{0}$ are the original area and initial extensometer span, respectively. $\Delta s$ is the change in length in $\mathrm{mm}$. The strain is therefore an average over the extensometer span. Using the method of toe compensation [24] the linear part of the stress strain diagram was extended to the zero stress axis to obtain the corrected zero strain point.

From the Force and displacement vectors resulting from the experimental results the mechanical work $\mathrm{W}$, required for the material to fail can be calculated. The mechanical work is the amount of energy transferred by a force acting over a distance in a certain direction.

$W_{f}=\int_{s=0}^{s=s_{f}} F d s$

Subscript $f$ above refers to mechanical failure at maximum stress. This work was determined by numerical integration using the trapezoidal rule with MATLAB [25], calculating discretely the following definite integral:

$W_{f}=\sum_{i=1}^{i=i_{f}}\left(s_{i}-s_{i-1}\right) f_{i}\left(\frac{s_{i}+s_{i-1}}{2}\right)$

Here, $\mathrm{s}_{\mathrm{i}}$ and $\mathrm{s}_{\mathrm{i}-1}$ are consecutive displacement segments. The slope of the linear portion of the stress-strain curve at small strains is the Elastic modulus $\mathrm{E}$ and was calculated as:

$E=\frac{\Delta \varepsilon}{\Delta \sigma}$ 
The slope of the softening part of the stress-strain diagram after failure is indicative of softening of the material and is calculated as:

$D=-\frac{\Delta \sigma}{\Delta \varepsilon}$

\section{Maximum Tensile Stress, $\sigma$}

As shown previously [7], several factors influence the nominal tensile stress of bitumen films. With increasing deformation rate, tensile strength increases, with increasing temperature and thickness, tensile strength decreases. The present experimental results show that in the absence of water conditioning, at $23^{\circ} \mathrm{C}$, the effect of adherend was minimal i.e. both composite materials $\mathrm{A}$ and $\mathrm{B}$ exhibited similar maximum tensile stresses with mineral aggregate or steel adherends (Figs. 9 and 10, Tables 3 and 7). At $23^{\circ} \mathrm{C}$ the average maximum tensile stress obtained in all tests of composite material A (bitumen) was 2.32 times higher than for composite material $\mathrm{B}(\mathrm{PmB})$ with $388 \mathrm{kPa}$ and $167 \mathrm{kPa}$ respectively. At $-10^{\circ} \mathrm{C}$ tensile strength of material $\mathrm{A}, \mathrm{B}, \mathrm{Ab}$ and $\mathrm{Bc}$ were $9.75,6.64,8.08$ and 8.17 times more than the values obtained at $23^{\circ} \mathrm{C}$.

The effect of water conditioning on maximum tensile stress was more noticeable in the presence of mineral aggregates than in the presence of steel adherends as shown in the Fig. 9( $(\mathrm{a}$ and $\mathrm{b})$. A reduction of tensile strength of $45 \%$ for material $\mathrm{Ab}$ and $30 \%$ for material $\mathrm{Bc}$ was calculated. In the absence of the mineral aggregates, the average maximum tensile stress of B was not affected by water conditioning whereas the tensile strength of $\mathrm{A}$ was reduced by $12 \%$. This could be attributed to the hydrophylicity of aggregate used in $\mathrm{A}$ as a result of its composition. These results demonstrate that depending on the type of aggregate, they can facilitate the sorption of water molecules and the resulting reduction in mechanical properties.

Marek and Herrin have shown that in binder films, for straight run bitumen, the penetration grade had a significant effect on the tensile strength [7]. Even though $\mathrm{B}$ is polymer modified, this fact was confirmed for the investigated materials both at $23^{\circ} \mathrm{C}$ and at $-10^{\circ} \mathrm{C}$ as material A (Pen 18) had consistently a higher tensile strength than B (Pen 50).

In practice and at the macro scale $(150 \mathrm{~mm} \varnothing)$, water sensitivity of asphalt concrete is determined through the indirect tensile strength ratio (ITSR) determined through indirect tensile tests using European standards [26]. ITSR is the ratio of the average indirect tensile strength of the wet group to the average indirect tensile strength of the dry group. The ITSR values for $150 \mathrm{~mm}$ cylindrical samples from cores taken from the road that (a)

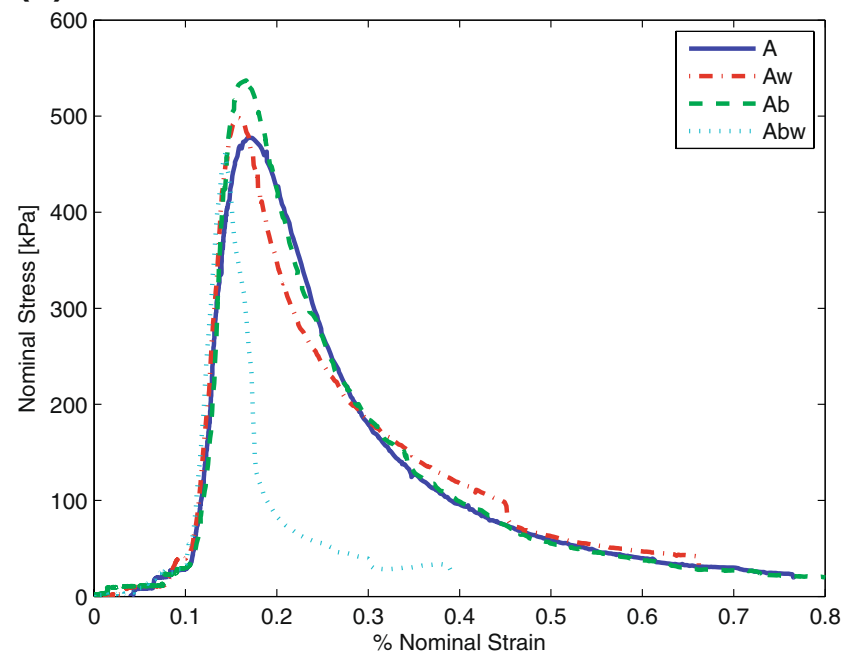

(b)

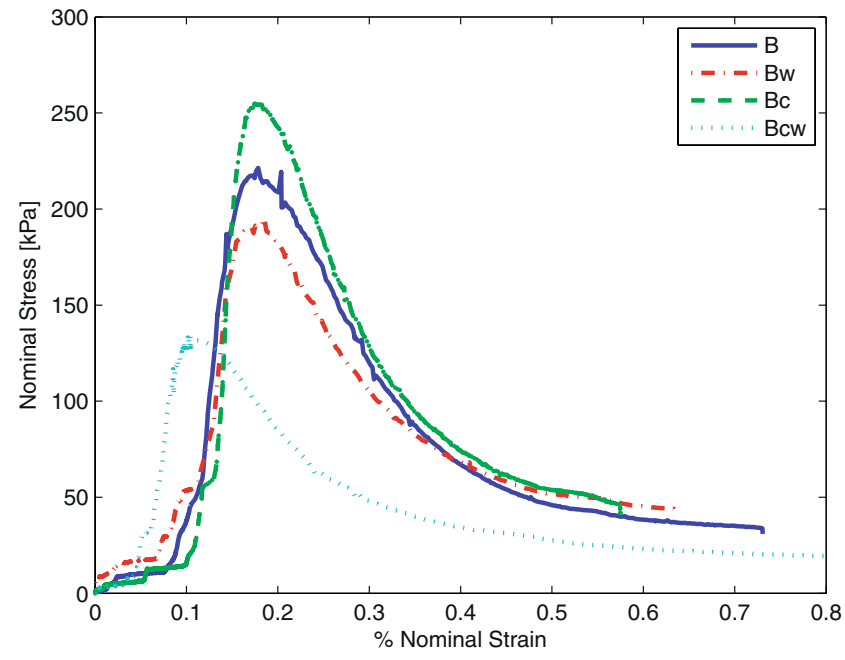

Fig. 9 (a) Stress-strain diagram of specimen type A (a) and specimen type $\mathrm{B}(\mathbf{b})$ at $23^{\circ} \mathrm{C}$. Both exhibited ductile fracture with binder $\mathrm{B}$ showing more viscous flow

materials $\mathrm{A}$ and $\mathrm{B}$ were based on were 0.5 and 0.7 , respectively [8]. To this end, this is in very close agreement to the ratio obtained by the microscale experiments, especially in the cases with mineral aggregate adherend. As presented in Table 6, the ratios of 0.55 and 0.7 for $\mathrm{Abw} / \mathrm{Ab}$ and $\mathrm{Bcw} / \mathrm{Bc}$, respectively, were found. Further investigations are needed to establish a definitive relationship between the water sensitivity in the macro and micro scales.

\section{Elastic Modulus, E}

As discussed earlier, the elastic behaviour of polymers is primarily affected by the intermolecular bonds between the chains, rather than by the covalent bonds within the molecules. Hence, it is mostly the weak, intermolecular 




Fig. 10 Stress-strain diagram of binder $A$ and binder $B$ at $-10^{\circ} \mathrm{C}$. Both exhibited brittle fracture with binder B showing some flow

van der Waals, dipole or hydrogen bonds that are contributing to elastic deformation. This is due to the fact that the covalent bonds are much stronger and cannot be mobilized as long as the weaker bonds can deform. Only if the chain molecules are aligned in parallel can the covalent bonds contribute [21].

The polymer modification in binder $\mathrm{B}$ is SBS, an elastomer, which is characterized by additional covalent cross-links between the chain molecules. In the elastic region these chain bonds do not contribute to the elastic properties significantly since in the elastic region primarily the straightening and disentanglement of the chains occur [20, 21].

High values of the elastic Modulus indicate that high forces are required to separate and untangle the molecular chains and cause the material to stretch elastically.

Mean values of elastic modulus for all samples are listed in Table 3. At the deformation rate of $0.1 \mathrm{~mm} / \mathrm{min}$, composite material $\mathrm{A}$ had an average elastic modulus at $23^{\circ} \mathrm{C}$ of $1,195 \mathrm{kPa}$, whereas material $\mathrm{B}$ had an average elastic modulus of $580 \mathrm{kPa}$. This indicates that at $23^{\circ} \mathrm{C}$ material A was 2 times stiffer than material B. Water conditioning resulted in more scatter in the results of the elastic modulus of material $A$ and a clear reduction of the elastic Modulus for material $\mathrm{B}(\mathrm{Bw}$ and $\mathrm{Bcw}$ ) and to a lesser extent in material A.

Comparing the effect of adherend in wet and dry states, it can be seen from Tables 3 and 6 that the adherend affected the elastic modulus of material A significantly more than material B both in the water conditioned state $(34 \%$ vs. $-0.05 \%)$ and not conditioned state $(38 \%$ vs. $15 \%)$. As seen for tensile stress, these results demonstrate that aggregates can facilitate the sorption of water molecules and the resulting reduction in elastic moldulus.
Ductility

The ductility is represented here by $\mathrm{D}$, the maximum slope of the stress-strain diagram after maximum stress. i.e. larger negative slopes indicate that in the softening portion of the stress strain diagram, the material is less ductile. Tables 3 and 4 present calculated mean values. Comparing overall values of material $\mathrm{A}$ and material $\mathrm{B}$ at $23^{\circ} \mathrm{C}$ with $\mathrm{D}_{\mathrm{A}}=323 \mathrm{kPa}$, and $\mathrm{D}_{\mathrm{B}}=72 \mathrm{kPa}, \mathrm{A}$ was found to be 4.5 times less ductile than $\mathrm{B}$ in the softening range of the diagram. In addition, visually examining individual experiments showed that the water conditioned samples had lost considerably in viscous-flow capability and as a result in ductility. As shown in the sample Bw [Fig. 7(c)] an increase in the formation and growth of voids and filamentation process led to failure. This can be seen in the slope of specimen Abw after peak stress in comparison to others (Fig. 9). The ductility of material B did not exhibit such water sensitivity as shown in Tables 3, 4, 6 and 7. This phenomenon can be explained from a molecular point of view. During water conditioning water molecules diffuse into the binder and occupy positions within the bitumen molecular chains and cause chain separation. As discussed earlier, the SBS elastomer contains cross links between the chains that keep the chains together, form a network and contribute to the ductility of the material.

As shown in Fig. 8, for the functionality of the material in situ, ductile behaviour is very important as it provides some tension transfer between the aggregates even after mechanical failure at maximum load. The observations of the binder films after reaching maximum tensile stress indicated that binder B continued to bridge the aggregates through the appearance of fibrils as shown in Fig. 7(b) (stage 3 in Fig. 6) demonstrating more desirable characteristic for in situ performance than a binder forming fewer fibrils before separation such as in Material A.

Furthermore the work required for the material to fail, i.e. reach maximum load, was calculated; on average it took twice the energy for material A to fail as for material B (Tables 4, 5, 6 and 7). On the other hand, the final

Table 4 Comparison of mean mechanical properties at $23^{\circ} \mathrm{C}$

\begin{tabular}{lrrr}
\hline Specimen & \multicolumn{1}{c}{ All A } & \multicolumn{1}{c}{ All B } & A/B \\
\hline Fmax [N] & 2.88 & 1.24 & 2.32 \\
$\sigma \max [\mathrm{kPa}]$ & 388.06 & 167.02 & 2.32 \\
$\varepsilon @$ omax [\%] & 0.06 & 0.03 & 1.71 \\
$\mathrm{~W}$ failure $[\mu \mathrm{J}]$ & 102.36 & 44.73 & 2.29 \\
$\mathrm{E}[\mathrm{kPa}]$ & 1195.38 & 579.60 & 2.06 \\
$\mathrm{D}[\mathrm{kPa}]$ & -323.29 & -71.89 & 4.50 \\
\hline
\end{tabular}


Table 5 Comparison of mean mechanical properties: effect of temperature

\begin{tabular}{lllllll}
\hline \multicolumn{7}{c}{ Effect of temperature } \\
\cline { 2 - 7 } Specimen & $\mathrm{A}(-10) / \mathrm{A}(23)$ & $\mathrm{B}(-10) / \mathrm{B}(23)$ & $\mathrm{Ab}(-10) / \mathrm{Ab}(23)$ & $\mathrm{Bc}(-10) / \mathrm{Bc}(23)$ & $\mathrm{A}(-10) / \mathrm{B}(-10)$ & $\mathrm{Ab}(-10) / \mathrm{Bc}(-10)$ \\
\hline Adherend & steel & steel & aggregate & aggregate & steel & aggregate \\
omax [N] & 9.75 & 6.64 & 8.08 & 8.17 & 4.10 & 2.36 \\
$\varepsilon @$ omax [\%] & 0.21 & 1.50 & 0.67 & 0.14 & 0.20 & 8.32 \\
\hline
\end{tabular}

separation for material B was much later, with larger deformations.

Comparison of the elastic modulus and ductility of the two materials show that at the same temperature and deformation rate, material $\mathrm{A}$ is 2 times stiffer than $\mathrm{B}$ whereas $\mathrm{B}$ is 4.5 times more ductile.

\section{Conclusions}

A novel method for the fabrication and tensile testing of specimens with thin films of bituminous binders using different adherends was presented. The method was implemented using flat mineral aggregate and stainless steel adherends. Experiments allowed the observation of material behaviour above and below the glass transition temperature. Results of uniaxial tensile tests at $23^{\circ} \mathrm{C}$ and $-10^{\circ} \mathrm{C}$ on $20 \mu \mathrm{m}$ of thin films confirm that the tensile strength of bituminous films is strongly dependent on temperature and polymer modification, which clearly results in different failure mechanisms. At higher temperatures a reduction in tensile strength and enhancement of ductility was observed. The experimental setup allowed simultaneous visualization of the failure mechanism of bitumen thin films that was not possible by previous experimental setups. Four clear stages before failure were observed: initial, necking, voiding and filamentation and separation. Water conditioning reduced the softening characteristics of straight run bitumen and, to a lesser extent, polymer modified

Table 6 Comparison of mean mechanical properties: effect of water

\begin{tabular}{lllll}
\hline \multirow{2}{*}{ Specimen } & \multicolumn{4}{l}{ Effect of water } \\
\cline { 2 - 5 } & Aw/A & Abw/Ab & Bw/B & Bcw/Bc \\
\hline$\sigma \max [\mathrm{kPa}]$ & 0.84 & 0.55 & 1.10 & 0.70 \\
$\varepsilon @ \sigma \max [\%]$ & 1.02 & 0.93 & 1.61 & 0.19 \\
$\mathrm{~W}$ failure $[\mu \mathrm{J}]$ & 1.43 & 0.32 & 1.70 & 0.56 \\
$\mathrm{E}[\mathrm{kPa}]$ & 0.75 & 0.89 & 0.52 & 0.64 \\
$\mathrm{D}[\mathrm{kPa}]$ & 1.70 & 1.03 & 1.20 & 0.94 \\
\hline
\end{tabular}

bitumen. When the surfaces were properly prepared (free of oils and debris) and the adherend and adhesive heated, failure appeared exclusively ductile and cohesive at $23^{\circ} \mathrm{C}$, whereas at $-10^{\circ} \mathrm{C}$ a cohesive/adhesive brittle failure as well as cohesive brittle failure was observed. At $23^{\circ} \mathrm{C}$ materials failed above $0.03 \%$ strain and at $-10^{\circ} \mathrm{C}$ at above $0.01 \%$ strain.

It was possible to compare the samples with steel and mineral aggregate adherends regarding behaviour with and without water conditioning. Water conditioned samples with the aggregate adherend had lower elastic modulus, strength and strain at maximum stress and required less energy to failure. Using a mineral aggregate adherend did not influence the ductility. These results demonstrate that aggregates can facilitate the sorption of water molecules and the resulting reduction in mechanical properties. The most significant difference was in the reduction of energy to failure.

Porous asphalt binder - mineral aggregate combinations that were water sensitive in terms of standardized tests in the macro $(150 \mathrm{~mm} \varnothing)$ and mega scale (in situ) also showed reduction in tensile strength in the micro scale. Polymer modified binder-aggregate combinations were less water sensitive. Furthermore, these results show that polymer modification improved the low temperature micro-mechanical behaviour of bitumen as seen in the mega scale (porous asphalt in situ) and in macro scale $(150 \varnothing \mathrm{mm})$ confirming that it is in the microscale where performance determining phenomena find their origin.

Table 7 Comparison of mean mechanical properties: effect of adherend

\begin{tabular}{lcccc}
\hline \multirow{2}{*}{ Specimen } & \multicolumn{4}{l}{ Effect of adherend } \\
\cline { 2 - 5 } & $\mathrm{A} / \mathrm{Ab}$ & Aw/Abw & $\mathrm{B} / \mathrm{Bc}$ & $\mathrm{Bw} / \mathrm{Bcw}$ \\
\hline$\sigma \max [\mathrm{kPa}]$ & 1.00 & 1.52 & 0.85 & 1.34 \\
$\varepsilon @ \sigma \operatorname{cmax}[\%]$ & 0.69 & 0.75 & 0.83 & 7.07 \\
$\mathrm{~W}$ failure $[\mu \mathrm{J}]$ & 0.57 & 2.60 & 0.94 & 2.84 \\
$\mathrm{E}[\mathrm{kPa}]$ & 1.62 & 1.37 & 1.16 & 0.95 \\
$\mathrm{D}[\mathrm{kPa}]$ & 1.13 & 1.86 & 0.93 & 1.19 \\
\hline
\end{tabular}


Acknowledgements This research project has been funded by the Swiss National Science Foundation, research grant number 200021$118087 / 1$. The authors would like to acknowledge Mr. M. Rees for designing the grip system to hold the specimen and his support during the experiments and Mr. U. Hintermüller for help in designing the specimen fabrication set up.

\section{References}

1. Sandberg U, Ejsmont JA (2002) Tyre/road noise reference book. Informex, Kisa, Sweden (www.informex.info)

2. Poulikakos LD, Partl MN (2010) Investigation of porous asphalt microstructure using optical and electron microscopy. J Microsc 240(2):145-154

3. Elseifi MA, Al-Qadi IL, Yang, S-H, Carpenter S (2008) Validity of asphalt binder film thickness concept in hot-mix asphalt. Transportation Research Board, 87th annual meeting. Washington D.C. USA

4. Harvey JAF, Cebon D (2003) Failure mechanisms in viscoelastic films. J Mater Sci 38:1021-1032

5. Harvey JAF, Cebon D (2005) Fracture tests on bitumen films. J Mater Civ Eng, ASCE, (17) pp 99-106, Jan/Feb

6. Hammoum F, Chailleux E, Nguyen H-N, Erlacher A, Piau J-M, Bodin D (2009) Experimental and numerical analysis of crack initiation and growth in thin film of bitumen. Int J Road Mater, Pavement Des 10:39-61

7. Marek RC, Herrin M (1967) Tensile behavior and failure characteristics of asphalt cement in thin films. Asphalt Paving Technology AAPT 37:386

8. Poulikakos L, Pittet M, Junod A, Arnaud L, Simond E, Gubler R, Partl MN, Dumont AG (2006) Mechanical properties of porous asphalt, recommendations for standardization. Published by the Swiss association of road and transportation experts. VSS report No. 1185

9. Poulikakos LD, Partl MN (2009) Evaluation of moisture susceptibility of porous asphalt concrete using water submersion fatigue tests. Constr Build Mater 23:3475-3484. doi:10.1016/j.conbuildmat. 2009.08.016

10. Swiss standard SN 640 431-7 NA (2008) Asphalt-Offenporiger Asphalt, National Annex to the European Standard EN 13108-7 (2008): bituminous mixtures-materials specifications-porous asphalt part 7
11. Cheng D, Little DN, Lytton R, Holste JC (2003) Moisture damage evaluation of asphalt mixtures by considering both moisture diffusion and repeated-load conditions. Transportation research record No. 1832, TRB, National research council, Washington D.C, pp 42-49

12. Kringos N (2007) Modeling of combined physical-mechanical moisture damage in asphalt mixes. PhD Dissertation University of Delft, the Netherlands

13. Sengoz B, Isikyakar G (2008) Analysis of styrene butadiene styrene polymer modified bitumen using fluorescent microscopy and conventional test methods. J Hazard Mater 150:424432

14. Web site of the Balmholz quarry: www.balmholz.ch. Accessed on 10.07.2008

15. Web site of the Famsa quarry: www.famsa.ch. Accessed on 10.07.2008

16. European Standard EN 1097-2 (2010) Test for mechanical and physical properties of aggregates-part 2: methods for determination of resistance to fragmentation. March 2010

17. European Standard EN 1097-8 (2009) Test for mechanical and physical properties of aggregates-part 8: determination of the polished stone value. July 2009

18. ISO 11357-1 (2009). Plastics-differential scanning calorimetry (DSC)

19. Reed, J., Whiteoak, D. (2003). The Shell bitumen handbook. Publisher Shell UK oil products

20. Calister WD (2003) Materials science and engineering, an introduction, 6th edn. Wiley, NJ, USA

21. Roesler J, Harders H, Baeker M (2007) Mechanical behavior of engineering materials, metals, ceramics, polymers, and composites. Springer, Berlin

22. Cerda E, Mahadevan L (2003) Geometry and physics of wrinkling. Phys Rev Lett 90(7):074302/1-4

23. Yao M, Mckinley G (1998) Numerical simulation of extensional deformations of voscoelastic liquid bridges in filament stretching devices. J Non-Newton Fluid Mech 74:47-88

24. ASTM D638-08 (2008) Standard test method for tensile properties of plastics

25. MATLAB version 7.3.06 (R2006b), Mathworks Inc

26. EN 12697-12 (2003) European standard, bituminous mixturestest method for hot mix asphalt-part 12: determination of the water sensitivity of bituminous specimens, Dec 